\title{
The influence of parameters variability on biomass selection for energy use
}

\author{
María Elena Arce
}

\begin{abstract}
Background: Biomass selection integrates heterogeneous variables such as fuel composition, fuel morphology and operating conditions. One important challenge in fuel selection field is to determine the influence of each individual variable in the combustion process to obtain the most efficient energy.

Methods: This paper investigates an optimization design of different combustion parameters for biomass combustion in fixed-bed counter-current boiler. A new application of error propagation theory (EPT) and grey relational analysis (GRA) has been proposed to analyse the combined effect of the most influential variables in the operating conditions; i.e. the ignition mass flux and the maximum temperature. This methodology combines the GRA to rank the alternatives and EPT to compute input measurement uncertainty propagation through the subsequent computing operations.

Results: The behaviour of seven biomasses [i.e. brassica pellet, poplar pellet, refuse-derived fuel pellet, wood pellets, almond shell and olive stone] that are readily available in Spain, in southern Europe, was analysed. The results presented are based on 43 experimental tests with these fuels.

Conclusions: This paper proposes a new tool based on grey relational analysis and error propagation theory, for making quick and easy decisions regarding fuel performance. The main advantages of this new tool are its simplicity, versatility and reliability, which have been verified by comparing obtained results with other studies. The influence of operational parameters and fuel properties were analysed. The results showed that air supply injected on the bed basis and size particle are the most influenced variables on the combustion.
\end{abstract}

Keywords: Fuel behaviour; Fixed-bed combustion; Parameters variability; Multi-criteria analysis; Energy efficiency

\section{Background}

The widespread use of biomass for power generation has led to the expansion of the types of fuels used. These types of fuels are highly versatile when undergoing energy conversion treatments and differ significantly from each other in efficiency [1]. Although various thermochemical processes can obtain energy from biomass, combustion is the most widely used [2].

Research related to the combustion of biomass focuses on improving both the properties of the fuels and the characteristics of the boilers [3]. Thus, many projects have attempted to validate mathematical models of biomass combustion processes based on experimental data obtained from experimental plants [4]. Fixed-bed combustion

Correspondence: elena.arce@cud.uvigo.es

Defense University Center at Spanish Naval Academy (Marin), Plaza de España 2, 36920 Marín, Spain technology is the most widely used because of its simplicity [5].

The main influences on the combustion process have been determined by research conducted in experimental plants and can be grouped into the following: fuel composition, fuel morphology and operating conditions [6]. No single criterion can be used to select the best fuel performance due to the multitude of influential parameters in the fixed-bed combustion process [7]. The ignition front velocity, the air mass flow rate and the maximum temperature reached are the most influential variables in the operating conditions $[7,8]$. Both variables depend on the air flow injected on the bed. In this context, determining the influence of each individual variable in the combustion process to select the most efficient fuel is a primary research focus [8]. The problem with determining combustion process of influential variables

\section{穴}

(c) 2015 Arce; licensee Springer. This is an Open Access article distributed under the terms of the Creative Commons Attribution License (http://creativecommons.org/licenses/by/4.0), which permits unrestricted use, distribution, and reproduction in any medium, provided the original work is properly credited. 
lies with the fact that parameters are interrelated. That is, it is a multi-criteria decision-making problem [9].

Thus, most papers published on this issue are based on statistical techniques such as multivariate data analysis [10] or mathematical models of dependence [11-13]. These multi-criteria decision analysis methods are used as tools for the classification and selection of the best alternative amongst a set of options. However, these analysis techniques have the disadvantage of requiring a minimum quantity of data for application, and for technical or economic reasons, this requirement cannot always be met. Therefore, grey relational analysis (GRA) was proposed [14] for accommodating inadequate data systems and solving decision-making problems in which there are multiple interrelated criteria [15]. This tool has been largely applied to multi-criteria decision-making problems in addition to energy systems, both the fuel selection and combustion process analysis [16-19].

In the biomass combustion process, several variables are optimised in opposite directions (i.e., minimise the maximum temperature and maximise the ignition mass flux), which leads to increased difficulty in multi-objective processes. In these cases, no single best alternative exists [20]. Grey relational analysis classifies different input sequences by determining the grey relational grade (GRG) [21]. Higher GRG values indicate better alternatives. Moreover, GRA may process a large number of variables independent of the measuring units [22].

This method facilitates the selection of the best alternative because it optimises a single GRG rather than multiple parameters. In addition, GRA identifies the factors that significantly influence the process [18]. However, the GRA does not consider the uncertainty in the measurements [23]. This omission can lead to confusion from similar GRGs measured at different positions or find that the GRG is uninteresting because of its high variability. In this study, the GRA is applied by selecting the best biomass fuel using the minimisation of the maximum temperature and the maximisation of the ignition mass flux as criteria. Experimental data are subject to measurement error; thus, the variable measurement error should be considered to determine how the error propagates through the operations [24]. Otherwise, factors that also influence the GRG may be not be considered, which could affect the GRG interpretation and selection [23].

\section{Methods}

\section{Experimental plant}

The experimental plant (Figures 1 and 2) and the subsequent discussion indicate that the results of this study are based on data presented by our research team [5]. The burner is a cylindrical steel tube with a diameter of 20 times the particle size to avoid edge effects resulting in the emission of product gas directly to the atmosphere [25].

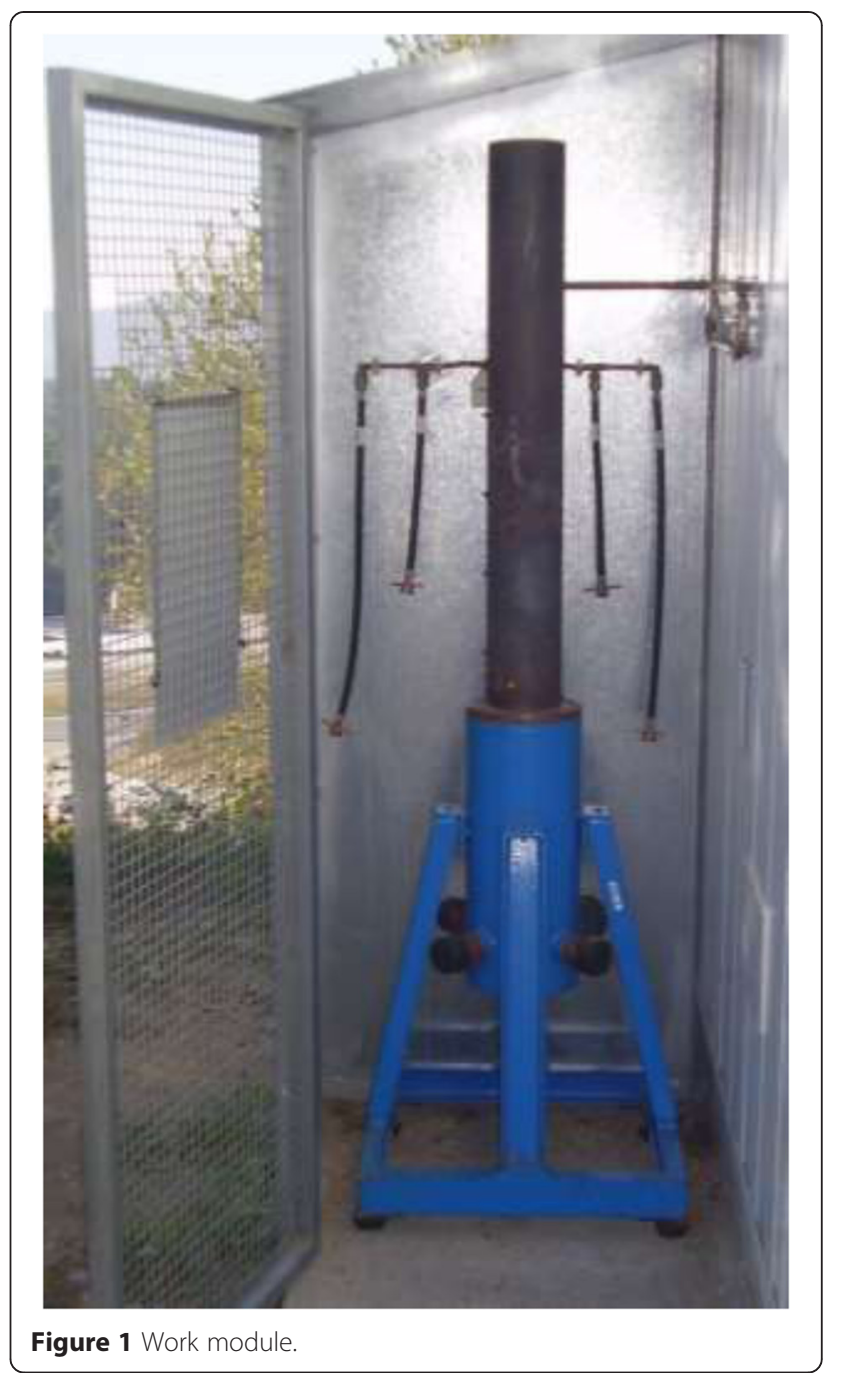

Along the tube, 12 type- $\mathrm{K}$ thermocouples are installed and distributed helically. The time required to reach a predetermined temperature between two adjacent thermocouples is used to calculate the velocity of the ignition front. The distances between the thermocouples are known with an associated uncertainty in both the temperature and position. Data from first and final thermocouples are rejected because in the first thermocouples the initial combustion phase is unstable and in the last thermocouples resonance phenomena appear [25]. The fuel is introduced in batches, forming the fixed bed. Each test is developed with a single fuel charge. The different air mass flow rates are supplied by a centrifugal fan and controlled by a flow meter. Figure 1 provides scheme of the tube. The plenum located on the tube is designed to ensure that the air flow in the output grate is homogeneous and completely developed.

\section{Fuels}

Seven different types of biomass found in southern Europe [26] were selected to include as many experimental 


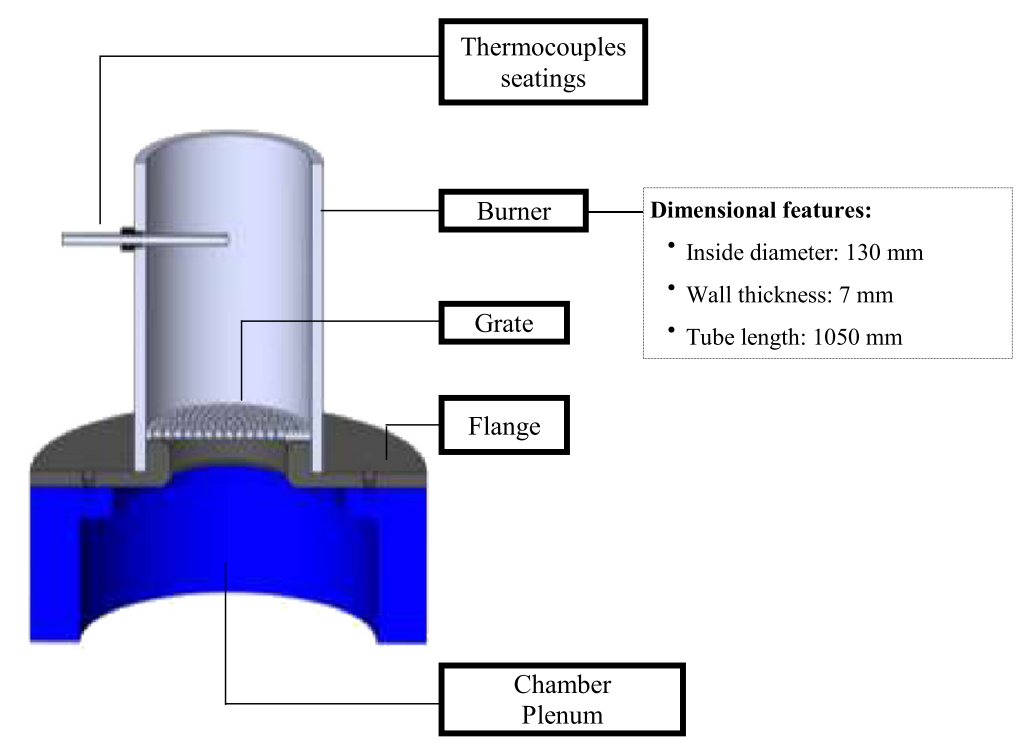

Figure 2 Detailed image of the joint between the plenum and the bottom tube base.

parameters as possible (for a more detailed description, see [5]) (Table 1). Five of them are pelletised fuels; two are mixed woods (wood pellet type 1, wp1, and wood pellet type 2, wp2). Two were derived from energy crops (brassica pellet, bp, and poplar pellet, pp), and one is made from municipal solid waste (rdfp). In addition, almond shell (as) reclaimed from the nut industry and olive stone (os), whose morphology is similar to a pellet but its composition and combustion behaviour are different, was used.

The immediate analysis (Figure 3 ) shows similar water content for the pellets (6\% to $9.8 \%$ ) except in the refusederived fuel pellet (rdfp) (17.9\%), which is due to its origin and manufacturing process. The highest ash content levels were found in refuse-derived fuel pellet and the brassica pellet (13.4\% and $7 \%$, respectively), while the lowest ash contents were found in the almond shell and olive stone $(0.6 \%$ in both cases). The minimal air requirement range varies from 4.39 (rdfp) to 6.96 (wp2). Wood pellet \#2 also has the highest low calorific value $\left(18.3 \cdot \frac{\mathrm{MI}}{\mathrm{kg}}\right)$ and the lowest concentration of oxygen in the equivalent molecule $(0.55 \mathrm{~mol}$ oxygen per mol carbon). In terms of particle size (Er), lowest values were found in wood pellet \#1.

\section{Variables}

Fixed-bed combustion process is influenced by multiple parameters [7]. This process complexity means that there is no single criterion for fuel selection. Thus, studies need to focus on a small number of variables. The main parameters influencing the process have been identified in the literature as the maximum temperature, air excess and ignition mass flux [6,7]. These parameters

Table 1 Properties of biomass fuels

\begin{tabular}{|c|c|c|c|c|c|}
\hline Fuel type & Formula d.b.a.f. $^{a}$ & LHV (MJ kg ${ }^{-1}$ ) & Sa $(-)^{b}$ & $E r(\mathrm{~mm})^{\mathrm{c}}$ & $S^{d}$ \\
\hline Wood pellet \#1 (wp1) & $\mathrm{CH}_{1.48} \mathrm{O}_{0.71}$ & 16.3 & 5.79 & 3.8 & 0.87 \\
\hline Wood pellet \#2 (wp2) & $\mathrm{CH}_{1.49} \mathrm{O}_{0.55}$ & 18.3 & 6.96 & 4.4 & 0.84 \\
\hline Brassica pellet (bp) & $\mathrm{CH}_{1.41} \mathrm{O}_{0.78}$ & 13.1 & 5.21 & 4.1 & 0.86 \\
\hline Poplar pellet (pp) & $\mathrm{CH}_{1.55} \mathrm{O}_{0.75}$ & 14.9 & 5.59 & 4.2 & 0.85 \\
\hline RDF pellet (rdfp) & $\mathrm{CH}_{1.48} \mathrm{O}_{0.57}$ & 14.6 & 4.39 & 7.4 & 0.87 \\
\hline Olive stone (os) & $\mathrm{CH}_{1.50} \mathrm{O}_{0.64}$ & 15.3 & 6.26 & 4.2 & 0.98 \\
\hline Almond shell (as) & $\mathrm{CH}_{1.40} \mathrm{O}_{0.68}$ & 15.6 & 5.89 & 6.5 & 0.54 \\
\hline
\end{tabular}

${ }^{\mathrm{a}}$ Dry basis ash free.

${ }^{\mathrm{b}} \mathrm{Kg}$ of dry air per kg of fuel burnt.

${ }^{\mathrm{C}}$ Radius of equivalent sphere. $E_{r}=\left(\frac{3 S_{\mathrm{vol}}}{4 \pi}\right)^{1 / 3} ; S_{\mathrm{vol}}$ sphere volume $\left(\mathrm{mm}^{3}\right)$.

${ }^{\mathrm{d}}$ Sphericity. $S=\frac{\pi^{1 / 3}\left(6 V_{p}\right)^{2 / 3}}{A_{p}} ; V_{p}$ volume of the characteristic particle $\left(\mathrm{m}^{3}\right) ; A_{p}$ surface area of the characteristic particle $\left(\mathrm{m}^{2}\right)$. 


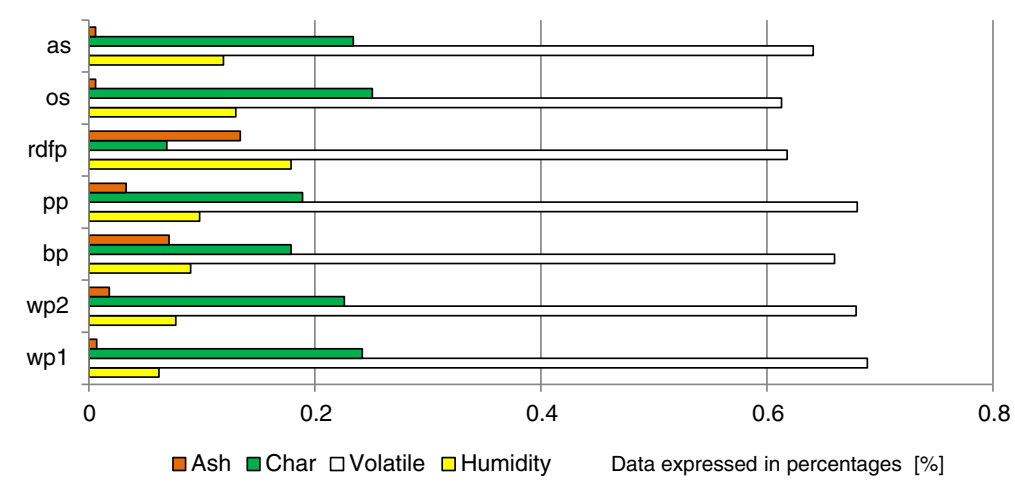

Figure 3 Properties of biomass fuels (immediate analysis, wet and ash basis).

provide information regarding fuel composition, morphology and the characteristics of the bed. These studies found that air excess is directly linked to the ignition mass flux and to the maximum temperature [13].

The fixed-bed combustion process is influenced by characteristic fuel-dependent parameters. The most important are as follows [11,27-29]:

- Particle size and shape

- Water, volatile and ash content

- Particle density, packing density and total porosity of the bed

- Calorific value

- Specific heat and thermal conductivity

The biomass parameters were considered constants for the purpose of this investigation, establishing that the packing density depends only on the particle size and shape [6].

The ignition mass flux (fuel mass burned) and the maximum temperature are dependent on the supplied air flow, which is controllable during the tests. Thus, the air mass flow rate is not used to calculate the GRG. In other words, the sequences analysed are combinations of the ignition mass flux and the maximum temperature. Furthermore, because the aim of this study is to choose the bestperforming fuel regardless of its composition or calorific value, other parameters need not be considered. A goodperforming fuel is generally one that achieves a high ignition mass flux with a low maximum temperature to avoid slag problems due to ash melting [30], which hampers the diffusion of the species and reduces the energy of the bed. However, the risk of ash melting is difficult to quantify because it is influenced by the temperature and other uncontrollable variables [31]. It is important to emphasize that ash melting temperature was not reached during fuel tests. On the basis of the above, the GRA may provide a useful tool for choosing a fuel based on its performance.

\section{Experimental methodology}

The experimental procedure may be summarised in the following steps [25] with the goal of avoiding the influence of other factors that could add additional uncertainty to the process. These eight procedures were rigorously followed during each test:

1. Move the combustor to the test area. The work module is connected to the power and control module through the air supply tube.

2. Place the grate at the bottom of the tube, and fill the tube with a fuel batch.

3. Introduce the thermocouples in their seatings, and ensure that they are straight and in the correct order.

4. Install the ignitor, and connect the temperature transducer power cables and the data bus.

5. Start the control panel and the data acquisition system.

6. Switch the ignitor feeding on, and start the test.

7. Remove the thermocouples from their seatings as the ignition front advances to protect them from the high temperatures. Once a thermocouple is removed, a hand-held probe is introduced in its seating to determine if the maximum ignition front temperature was reached.

8. Once the ignition front has run through the entire tube and the remains have been burnt over the grate, the test is complete.

\section{Grey relational analysis and error propagation Grey relational analysis}

The GRA method may be summarised into four steps:

Step 1 Data normalisation

The first step in GRA is to normalise the measurements in the range between zero and one. To do this, reference sequence must be defined (the smaller-the-better 
or the larger-the better: Equations 1 and 2, respectively). The purpose of this pre-processing is to obtain dimensionless variables to compare the different sequences. It should be noted that variables are expressed in different units and scales.

A grey system with a set of $I$ variables has $y_{i}$ dependent factors; the $J$ original measurement sequences may be normalised using the following expressions:

- If larger is the better:

$$
x_{i, j}=\frac{y_{i, j}-\min _{j} y_{i, j}}{\max _{j} y_{i, j}-\min _{j} y_{i, j}} \in[0,1] ; i=1, \ldots, I ; j=1, \ldots, J
$$

- If smaller is the better:

$$
x_{i, j}=\frac{\max _{j} y_{i, j}-y_{i, j}}{\max _{j} y_{i, j}-\min _{j} y_{i, j}} \in[0,1] ; i=1, \ldots, I ; j=1, \ldots, J
$$

For a given value of $i$, extreme values are achieved in the measurements $y_{i, m_{i}}=\min _{j} y_{i, j}$ and $y_{i, M_{i}}=\max _{j} y_{i, j}$ to yield $x_{i, m_{i}} \in\{0,1\}$ and $x_{i, M_{i}} \in\{0,1\}$

Step 2 Grey relational coefficient

After grey relational generation, the next step is to calculate the grey relational coefficient using Deng's formula as follows:

$$
\xi_{i, j}=\frac{\min _{i, j}\left(x_{i, 0}-x_{i, j}\right)+\zeta \max _{i, j}\left(x_{i, 0}-x_{i, j}\right)}{\left(x_{i, 0}-x_{i, j}\right)+\zeta \max _{i, j}\left(x_{i, 0}-x_{i, j}\right)} ; i=1, \ldots, I ; j=1, \ldots, J
$$

in which $\zeta$ represents the distinguishing coefficient $(0 \leq \zeta \leq 1) . x_{i, 0}$ is the normalised ideal result of the $i$ th variable and consequently, $x_{i, 0} \geq x_{i, j} ; j=1, \ldots, J$.

The grey relational coefficient range will compress depending on the value of the distinguishing coefficient [20].

Step 3 Grey relational grade

The grey relational grade (GRG), $\gamma$, is calculated based on the average of the grey relational coefficients.

$$
\gamma_{j}=\frac{1}{N} \sum_{i=1}^{I} \xi_{i, j} ; j=1, \ldots, I
$$

The GRG expresses the degree of correlation between the reference sequence (larger-the-better or smaller-thebetter) and the comparison sequence [32]. The best alternative is selected based on the grey relational grade (GRG) value.

Step 4 Grey relational rank
Once the GRG is calculated, the different sequences are ranked according to their GRG values. Higher values indicate better options [33]. That is, the higher the GRG is, the more similarity exists between the reference sequence and the compared sequence.

\section{Optimisation criterion}

The grey theory is applied in this study to select the best fuel and air flow rate configuration. The best configuration is that which has the highest ignition mass flux with the lowest maximum temperature.

The fuel selection criteria depend on the combustion process, thus requiring multiple selection procedures. The analysed factors were the composition, the morphology and the supplied air mass flow rate. The systematic and statistical uncertainties associated with measuring processes are considered in calculating the GRG. The total uncertainty is the quadratic sum of the systematic (nominal) and statistical (associated with uncontrollable parameters) uncertainties: $\sigma_{T}=\sqrt{\sigma_{N}^{2}+\sigma_{S}{ }^{2}}$ [5]. Within the total uncertainty, the uncertainty associated with the uncontrollable factors is shown to have a greater weight than the nominal uncertainty, in terms of both time and space [34]. The straightness of the thermocouples is an important parameter for calculating both the ignition front velocity and the maximum temperature. A thermocouple tip deflection may result to variable distances between the thermocouples, and this could cause variations in the ignition mass flux value because temperature waves could reach the thermocouple at different points. Thermocouple tip deflection was analysed; the average variability in the positioning is $2.06 \mathrm{~mm}$ [25]. The uncertainty in the process is also affected by the time variable because data signals are sent every $4 \mathrm{~s}$, while the thermocouple temperature time adaption requires less than a second. Thus, the limiting factor is the sampling time and the uncertainty may be expressed as $\Delta t=\Delta \bar{t} \pm 4 \mathrm{~s}$ [25]. Once the tests are performed and the uncertainties estimated, the uncertainty propagation can be calculated for each GRG to obtain the grey relational grade error (GRGe). The GRG value is not affected by the GRGe, but the GRGe provides additional information to facilitate the decision-making process.

\section{Error propagation}

To be thorough, measurement results should include information regarding uncertainty [35]. The uncertainty associated with a measurement represents the disparity between the measurement result and the actual measured value. Despite the importance of this parameter, it is not always quantified.

The EPT evaluates and quantifies how uncertainty in an input measurement is propagated to the final results. 


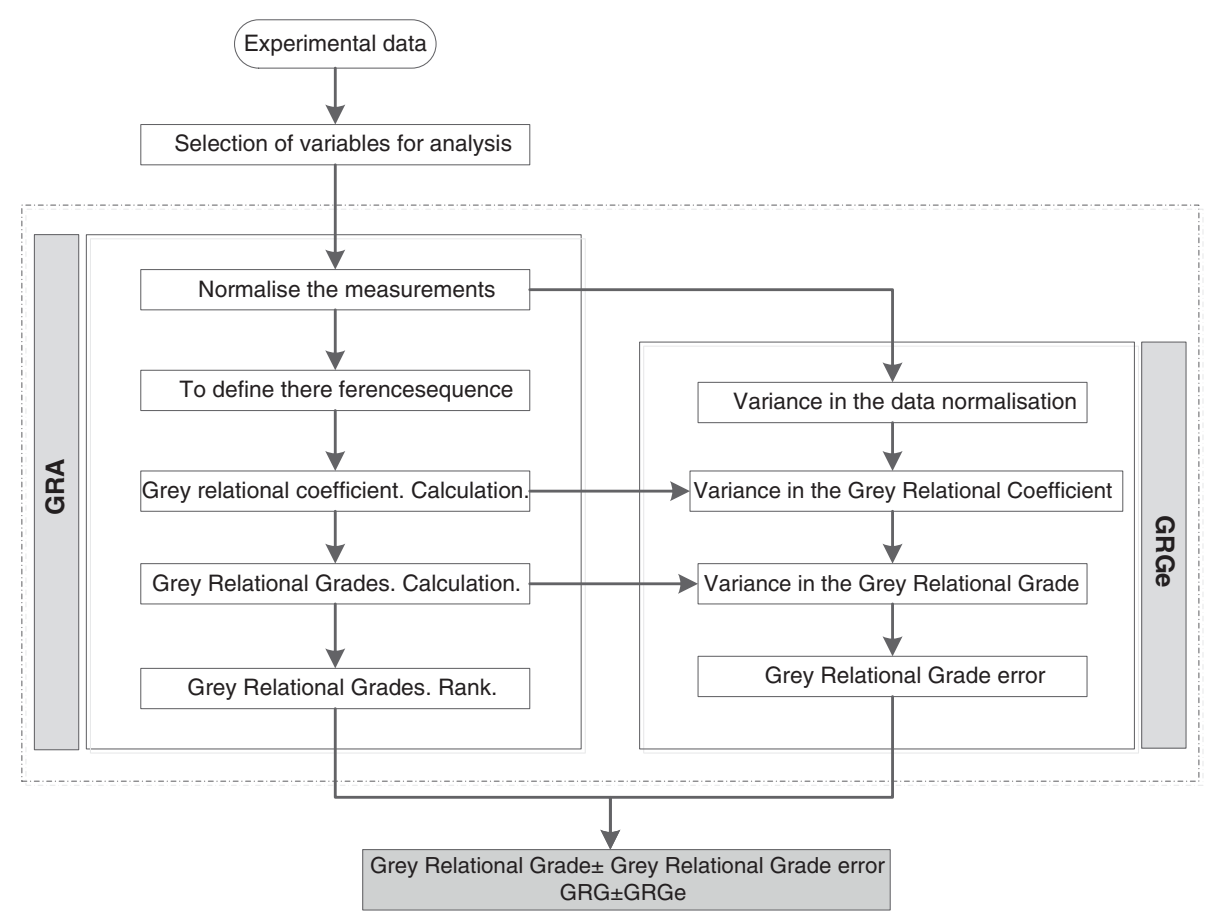

Figure 4 Calculation process scheme.

As the error associated with a variable combines other variable values, the error may not be calculated as the sum of the uncertainties in the constituent terms because the error would be overestimated. The error propagation theory allows one to know the error associated with the GRG, considering that the GRG is computed by averaging the grey relational coefficient corresponding to each process response. The error associated with the GRG calculation (GRGe) is determined by the following equation [22]:

$$
\Delta\left(\gamma_{j}\right) \approx+\sqrt{\sum_{i=1}^{I} \frac{1}{I^{2}} \sigma^{2}\left(\xi_{i, j}\right)+2 \sum_{i=1}^{I-1} \sum_{k=i+1}^{I} \frac{1}{I^{2}} \sigma\left(\xi_{i, j}\right) \sigma\left(\xi_{k, j}\right) \rho\left(\xi_{i, j}, \xi_{k, j}\right)}
$$

in which $\sigma\left(\xi_{k, j}\right)$ represents the grey relational coefficient error that depends on the error in initial uncertainty of the measurements and $\rho\left(\xi_{i, j}, \xi_{k, j}\right)$ is the correlation coefficient. Grey relational coefficient error quantifies how the initial uncertainty is propagated through the

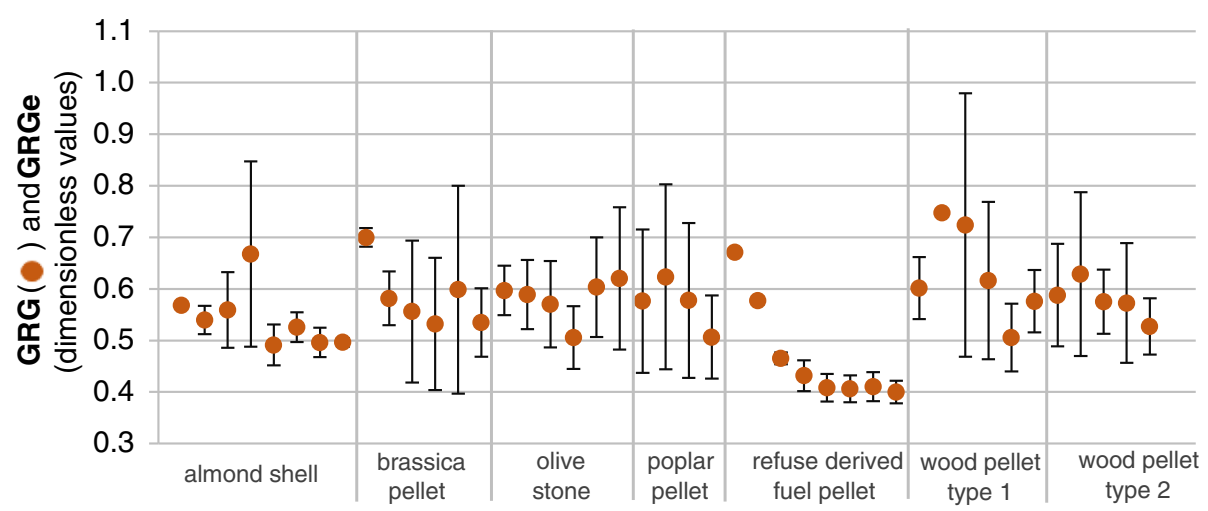

Figure 5 The GRG rank, GRG and GRGe values for seven fuels. Almond shell, brassica pellet, olive stone, poplar pellet, refuse-derived fuel pellet, wood pellet type 1, and wood pellet type 2. The GRGe is represented by the bars. 
Table 2 Experimental results, grey relational grade (GRG) and grey relational grade error (GRGe)

\begin{tabular}{|c|c|c|c|c|c|c|c|c|c|}
\hline Fuel & AMF & IMF & $\mathrm{AE}$ & MT & GRG & GRGe & GRGe(\%) & $\begin{array}{l}\text { Order } \\
\text { (GRG) }\end{array}$ & $\begin{array}{l}\text { Order } \\
(\mathrm{GRG}+\mathrm{GRGe})\end{array}$ \\
\hline \multirow[t]{8}{*}{ Almond shell (as) } & 0.08 & 0.02 & 0.65 & 800 & 0.57 & $4.51 \mathrm{E}-03$ & 0.79 & 24 & 5 \\
\hline & 0.13 & 0.04 & 0.52 & 910 & 0.54 & $2.72 \mathrm{E}-02$ & 5.04 & 27 & 12 \\
\hline & 0.15 & 0.05 & 0.57 & 1,000 & 0.56 & 7.31E-02 & 13.08 & 25 & 19 \\
\hline & 0.23 & 0.06 & 0.60 & 1,010 & 0.67 & $1.80 \mathrm{E}-01$ & 26.93 & 5 & 17 \\
\hline & 0.35 & 0.04 & 1.26 & 1,030 & 0.49 & 3.96E-02 & 8.07 & 37 & 29 \\
\hline & 0.38 & 0.04 & 1.53 & 940 & 0.53 & 2.91E-02 & 5.53 & 31 & 14 \\
\hline & 0.43 & 0.04 & 1.87 & 970 & 0.50 & $2.86 \mathrm{E}-02$ & 5.76 & 36 & 25 \\
\hline & 0.48 & 0.03 & 2.80 & 910 & 0.50 & $8.25 \mathrm{E}-03$ & 1.66 & 35 & 16 \\
\hline \multirow[t]{6}{*}{ Brassica pellet (bp) } & 0.08 & 0.04 & 0.39 & 740 & 0.70 & $1.79 \mathrm{E}-02$ & 2.56 & 3 & 2 \\
\hline & 0.15 & 0.05 & 0.49 & 910 & 0.58 & $5.18 \mathrm{E}-02$ & 8.91 & 16 & 8 \\
\hline & 0.18 & 0.06 & 0.55 & 1,240 & 0.56 & $1.38 \mathrm{E}-01$ & 24.76 & 26 & 36 \\
\hline & 0.23 & 0.06 & 0.72 & 1,300 & 0.53 & $1.28 \mathrm{E}-01$ & 24.10 & 29 & 37 \\
\hline & 0.35 & 0.07 & 0.97 & 1,290 & 0.60 & $2.01 \mathrm{E}-01$ & 33.66 & 12 & 39 \\
\hline & 0.38 & 0.05 & 1.38 & 1,040 & 0.53 & $6.64 \mathrm{E}-02$ & 12.42 & 28 & 24 \\
\hline \multirow[t]{5}{*}{ Olive stone (os) } & 0.13 & 0.05 & 0.42 & 880 & 0.60 & 4.79E-02 & 8.03 & 13 & 6 \\
\hline & 0.15 & 0.05 & 0.54 & 930 & 0.59 & $6.71 \mathrm{E}-02$ & 11.40 & 14 & 9 \\
\hline & 0.23 & 0.06 & 0.66 & 1,010 & 0.57 & 8.39E-02 & 14.71 & 23 & 18 \\
\hline & 0.28 & 0.05 & 0.87 & 1,100 & 0.51 & $6.08 \mathrm{E}-02$ & 12.03 & 33 & 30 \\
\hline & 0.35 & 0.06 & 0.85 & 960 & 0.60 & $9.65 \mathrm{E}-02$ & 15.99 & 10 & 13 \\
\hline \multirow[t]{5}{*}{ Poplar pellet (pp) } & 0.18 & 0.06 & 0.52 & 1,030 & 0.62 & $1.38 \mathrm{E}-01$ & 22.26 & 8 & 20 \\
\hline & 0.23 & 0.06 & 0.66 & 1,160 & 0.58 & $1.39 \mathrm{E}-01$ & 24.13 & 19 & 33 \\
\hline & 0.28 & 0.06 & 0.77 & 1,130 & 0.62 & 1.79E-01 & 28.77 & 7 & 31 \\
\hline & 0.33 & 0.06 & 0.94 & 1,200 & 0.58 & $1.50 \mathrm{E}-01$ & 26.05 & 17 & 34 \\
\hline & 0.43 & 0.05 & 1.33 & 1,170 & 0.51 & 8.06E-02 & 15.91 & 32 & 35 \\
\hline \multirow[t]{8}{*}{ Refuse-derived fuel pellet (rdfp) } & 0.05 & 0.02 & 0.53 & 730 & 0.67 & $3.59 \mathrm{E}-03$ & 0.54 & 4 & 3 \\
\hline & 0.08 & 0.03 & 0.61 & 810 & 0.58 & 7.45E-03 & 1.29 & 18 & 4 \\
\hline & 0.13 & 0.03 & 0.89 & 980 & 0.47 & 1.15E-02 & 2.46 & 38 & 28 \\
\hline & 0.15 & 0.04 & 0.96 & 1,180 & 0.43 & 2.99E-02 & 6.92 & 39 & 38 \\
\hline & 0.23 & 0.04 & 1.25 & 1,260 & 0.41 & 2.69E-02 & 6.59 & 41 & 41 \\
\hline & 0.23 & 0.04 & 1.58 & 1,250 & 0.41 & $2.60 \mathrm{E}-02$ & 6.40 & 42 & 42 \\
\hline & 0.33 & 0.04 & 1.80 & 1,250 & 0.41 & $2.80 \mathrm{E}-02$ & 6.82 & 40 & 40 \\
\hline & 0.35 & 0.04 & 2.13 & 1,240 & 0.40 & $2.18 \mathrm{E}-02$ & 5.46 & 43 & 43 \\
\hline \multirow[t]{5}{*}{ Wood pellet \#1 (wp1) } & 0.15 & 0.05 & 0.43 & 890 & 0.60 & $6.02 \mathrm{E}-02$ & 10.01 & 11 & 7 \\
\hline & 0.33 & 0.07 & 0.81 & 1,020 & 0.75 & 2.67E-03 & 0.36 & 1 & 1 \\
\hline & 0.35 & 0.07 & 0.98 & 990 & 0.72 & $2.55 \mathrm{E}-01$ & 35.28 & 2 & 23 \\
\hline & 0.43 & 0.06 & 1.21 & 1,040 & 0.62 & $1.53 \mathrm{E}-01$ & 24.76 & 9 & 26 \\
\hline & 0.48 & 0.05 & 1.63 & 1,100 & 0.51 & $6.55 \mathrm{E}-02$ & 12.95 & 34 & 32 \\
\hline \multirow[t]{2}{*}{ Wood pellet \#2 (wp2) } & 0.13 & 0.05 & 0.35 & 940 & 0.58 & $6.05 \mathrm{E}-02$ & 10.50 & 20 & 10 \\
\hline & 0.15 & 0.06 & 0.38 & 1,010 & 0.59 & $9.95 \mathrm{E}-02$ & 16.92 & 15 & 15 \\
\hline
\end{tabular}


Table 2 Experimental results, grey relational grade (GRG) and grey relational grade error (GRGe) (Continued)

\begin{tabular}{rrrrrrrrrr}
\hline 0.35 & 0.06 & 0.81 & 1,040 & 0.63 & $1.59 \mathrm{E}-01$ & 25.28 & 6 & 22 \\
0.43 & 0.05 & 1.04 & 930 & 0.58 & $6.22 \mathrm{E}-02$ & 10.81 & 21 & 11 \\
0.48 & 0.06 & 1.40 & 1,100 & 0.57 & $1.16 \mathrm{E}-01$ & 20.31 & 22 & 27 \\
& 0.50 & 0.05 & 1.44 & 1,010 & 0.53 & $5.46 \mathrm{E}-02$ & 10.35 & 30 & 21 \\
\hline
\end{tabular}

AMF, air mass flow $\left(\mathrm{kg} \mathrm{m}^{-2} \mathrm{~s}^{-1}\right)$; IMF, ignition mass flux $\left(\mathrm{kg} \mathrm{m}^{-2} \mathrm{~s}^{-1}\right) ; \mathrm{AE}$, air excess; IMFU, ignition mass flux uncertainty (kg $\left.\mathrm{m}^{-2} \mathrm{~s}^{-1}\right)$; $\mathrm{MT}$, maximum temperature $\left({ }^{\circ} \mathrm{C}\right)$.

calculations. It is important to remark that the GRG error is the result of the sequential calculation. That is, GRG error is determined from experimental data: input variable error propagation. Thus, the error propagation theory is an additional tool for GRA (Figure 4).

\section{Results and discussion}

The results presented herein are based on 43 experimental tests: eight almond shells (as), six brassica pellets (bp), five olive stones (os), five poplar pellets (pp), eight refuse-derived fuel pellets (rdfp), five wood pellet type 1 and six wood pellet type 2 .

After all GRGs and GRGes have been calculated, the data are sorted according to the GRG value (Figure 5 and Table 2). The high GRGe values in the sequences are due to the uncertainty and values of the variables.

Figure 5 shows the GRG rank indicating that the wp1 is the best option as confirmed by the fact that GRGe associated with the first wp1 GRG is sufficiently small. Figure 5 indicates that best fuel performances come from those in pellet form. This result is consistent with the literature research on the influence of morphology on the ignition mass flow rate [27]. The references also found that a small particle size is associated with a rapid devolatilisation and that spherical particles are linked with tighter packing. Bed porosity is affected by size and shape of the particles. Maximum ignition front propagation registered by wood pellet type 1 is based more on the small size particle, rather than the shape (sphericity).
Furthermore, pellet fuels have higher adiabatic temperatures [5].

In the specific case of the best alternative, wp1, the low water and ash content, together with and a small particle size and the characteristics of pellet fuels (high LHV and adiabatic temperature) caused the high GRG values that are consistent with those found in the literature $[5,25,36]$. This fact indicates that there is an inverse correlation between ash content and heating value, because the ash does not contribute significantly to the overall heat released $[37,38]$.

Figure 5 also demonstrates that olive stone behaves similarly to the pellet-shaped fuels likely because the olive stone morphology is similar to that of the pelletshaped fuels [5].

When data were analysed based on GRG + GRGe (Table 2), the order changes. This is because of the air excess coefficient influence. That is, the higher air excess coefficient used is, the worse combustion process efficiency is [39]. Previous works found that if oxygen supply increases, ignition mass flow increases until the reaction-limited mode is reached. This boundary line is defined by air excess. Moreover, air mass flow is a key factor to define and identify the combustion process regime. Three regimes were identified in fixed-bed combustion process: oxygen-limited mode, reaction-limited mode and extinction phase $[40,41]$. Best combinations attending GRG + GRGe criteria belong to reactionlimited mode, where maximum ignition flow values

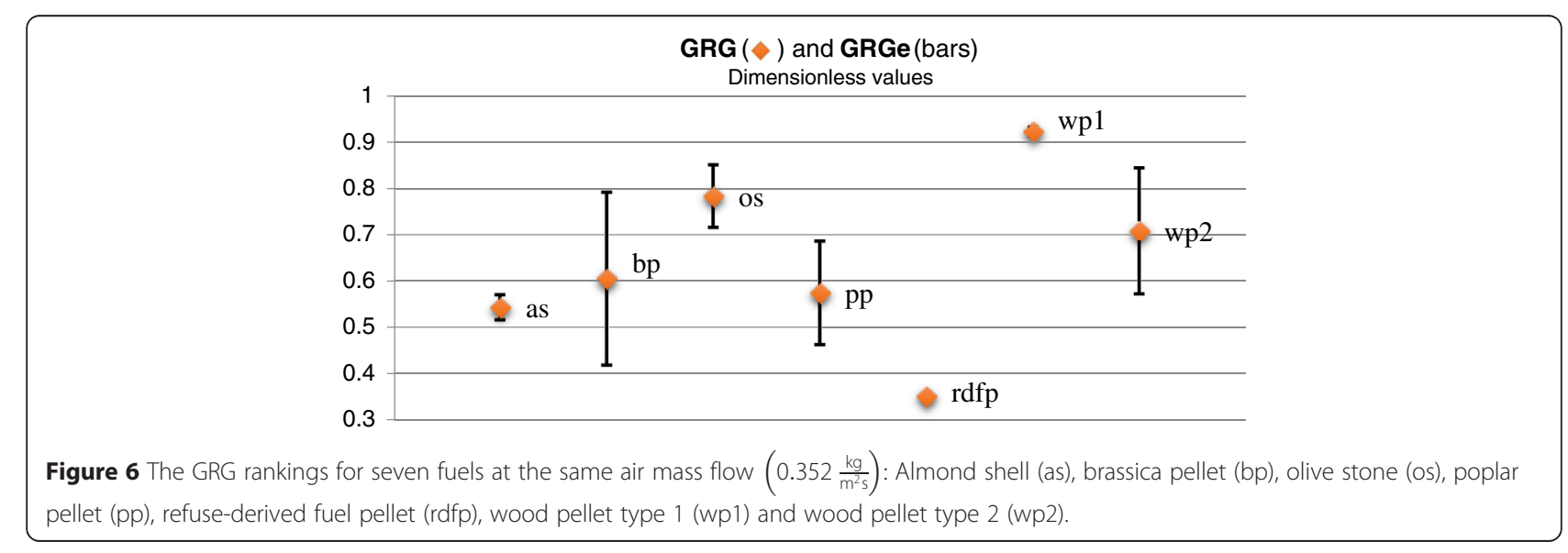


were reached. This phase is characterised by increasing primary air supply. In this regime, the ignition mass flow is controlled by the oxygen supply to it [40]. Optimal combustion conditions occur in the substoichiometric zone, because maximum rates are always reached under fuel-rich conditions [40]. As can be expected, optimal point conditions are a function of the fuel type.

It is important to point out the effect of maximum temperature uncertainty. Analysing changes in data order between the GRG rank and the GRG + GRGe rank, it is found that best alternatives are not related with points where highest maximum temperature values are obtained. This is due to the fact that maximum temperatures were registered with portable thermocouples which precision is reduced due to variability of the fit of thermocouples in their seatings.

Most of the studies on this subject indicate that the supplied air mass flow is the most important operative parameter [6].

The air mass flow range differs depending on the fuel because the ignition front is extinguished when certain air mass flows are applied. Thus, fewer sequences were examined in certain fuels such as olive stone or wood pellet 1 . In order to compare fuel performance under the same conditions, a common air mass flow was selected $\left(0.352 \frac{\mathrm{kg}}{\mathrm{m}^{2} \mathrm{~s}}\right)$.

Figure 6 indicates that wp1 remains the best option due to both the high GRG and to the small GRGe values. No significant changes in the rankings have been identified. The rdfp is clearly the worst option because of the tendencies exhibited in Figure 5. This variable rdfp behaviour is mainly due to its high water content that decreases the ignition mass flow velocity [25]. However, the water content does not affect the maximum temperature of the bed.

Thus, one can conclude that the fixed-bed combustion process is influenced by parameters that depend on the characteristics of the fuels. However, these parameters are interrelated, so selecting the best-performing fuel is difficult because their individual effects cannot be isolated and evaluated. Thus, the GRG + GRGe rank serves as a criterion for multi-objective decision-making.

\section{Conclusions}

In conclusion, this paper proposes and supports the effectiveness of the grey relational analysis and error propagation theory for making quick and easy decisions regarding fuel performance. The influence of operational parameters and fuel properties were analysed. The rank of the grey relational grade shows that morphology is a key factor on the combustion efficiency. The smaller size particle, the more bed porosity and heat transfer. In contrast, high water content in fuel composition is associated with low mass flow of ignition. However, the humidity does not affect the maximum temperature reached in the bed.

Fuel optimal conditions belong to the sub-stoichiometric regime. This fact reflects the importance of the adverse effect of convection counterflow fixed-bed combustion. Two value zones are distinguished in the GRG rank: sub-stoichiometric regime zone and excess air regime zone. This is due to the maximum combustion velocities that are reached in fuel-rich conditions. Naturally, the optimum point depends on the fuel analysed.

Besides, ignition mass flow, the other study parameter, is a function of air mass flow. Moreover, maximum temperature measurement uncertainty influence has to be considered on optimal fuel performance.

That is, air supply injected on the bed basis and size particle are the most influenced variables on the combustion. As can be expected, the ignition mass flux correlates greater with the size particle than with the air mass flow in order to select the best fuel combustion performance.

\section{Abbreviations}

AE: air excess; AMf: air mass flow; as: almond shell; bp: Brassica pellet; EPT: error propagation theory; GRA: grey relational analysis; GRG: grey relational grade; GRGe: grey relational grade error; GRGV: grey relational grade variation; IMF: ignition mass flux; IFMrc: ignition mass flux relational coefficient; IMFn: ignition mass flux normalised; IMFU: ignition mass flux uncertainty; IMFvn: ignition mass flux variation normalised; IMFvrc: ignition mass flux variation relational coefficient; LHV: low heating value;

MT: maximum temperature; MTn: maximum temperature normalised; MTrc: maximum temperature relational coefficient; MTU: maximum temperature uncertainty; MTvn: maximum temperature variation normalised; MTvrc: maximum temperature variation relational coefficient; os: olive stone; pp: poplar pellet; rdfp: refuse-derived fuel pellet; wp1: wood pellet type 1; wp2: wood pellet type 2 .

\section{Competing interests}

The authors declare that they have no competing interests.

\section{Authors' contributions}

The author conducted the analysis and drafted the manuscript.

Received: 26 November 2014 Accepted: 26 March 2015

Published online: 28 April 2015

\section{References}

1. Mehrabian R, Zahirovic S, Scharler R, Obernberger I, Kleditzsch S, Wirtz S, Scherer V, Lu H, Baxter LL (2012) A CFD model for thermal conversion of thermally thick biomass particles. Fuel Process Technol 95:96-108, doi:10.1016/j.fuproc.2011.11.021

2. European Environmental Agency (2013) EN16 Final energy consumption by sector, http://www.eea.europa.eu/data-and-maps/indicators/final-energyconsumption-by-sector-5/assessment. Accessed 21 Jul 2014

3. Chaney J, Liu H, Li J (2012) An overview of CFD modelling of small-scale fixed-bed biomass pellet boilers with preliminary results from a simplified approach. Energ Convers Manage 63:149-156, doi:10.1016/j.enconman. 2012.01.036

4. Porteiro J, Patino D, Miguez JL, Granada E, Moran J, Collazo J (2012) Study of the reaction front thickness in a counter-current fixed-bed combustor of a pelletised biomass. Combust Flame 159:1296-1302, doi:10.1016/ j.combustflame.2011.10.007 
5. Porteiro J, Patino D, Collazo J, Granada E, Moran J, Miguez JL (2010) Experimental analysis of the ignition front propagation of several biomass fuels in a fixed-bed combustor. Fuel 89:26-35, doi:10.1016/j.fuel.2009.01.024

6. Porteiro J, Patino D, Moran J, Granada E (2010) Study of a fixed-bed biomass combustor: influential parameters on ignition front propagation using parametric analysis. Energy Fuel 24:3890-3897, doi:10.1021/ef100422y

7. Horttanainen M, Saastamoinen J, Sarkomaa P (2002) Operational limits of ignition front propagation against airflow in packed beds of different wood fuels. Energy Fuel 16:676-686, doi:10.1021/ef010209d

8. Miranda T, Arranz JI, Montero I, Roman S, Rojas CV, Nogales S (2012) Characterization and combustion of olive pomace and forest residue pellets. Fuel Process Technol 103:91-96, doi:10.1016/j.fuproc.2011.10.016

9. Arce ME, Saavedra A, Míguez JL, Granada E, Cacabelos A (2013) Biomass fuel and combustion conditions selection in a fixed bed combustor. Energies 6:5973-5989, doi:10.3390/en6115973

10. Arshadi M, Gref R, Geladi P, Dahlqvist S, Lestander T (2008) The influence of raw material characteristics on the industrial pelletizing process and pellet quality. Fuel Process Technol 89:1442-1447, doi:10.1016/j.fuproc.2008.07.001

11. Bidabadi M, Abedinejad MS, Fereidooni J (2011) Modeling of the propagation of a reaction front in fixed bed combustion of wood particles. J Mech 27:453-459, doi:10.1017/jmech.2011.48

12. Haseli Y, van-Oijen JA, de-Goey LPH (2011) A detailed one-dimensional model of combustion of a woody biomass particle. Bioresource Technol 102:9772-9782, doi:10.1016/j.biortech.2011.07.075

13. Sefidari H, Razmjoo N, Strand M (2014) An experimental study of combustion and emissions of two types of woody biomass in a 12-MW reciprocating-grate boiler. Fuel 135:120-129, doi:10.1016/j.fuel.2014.06.051

14. Deng J (1989) Introduction to grey system theory. J Grey Syst 1:1-24

15. Sakthivel G, Ilangkumaran M, Nagarajan G, Priyadharshini GV, Kumar SD, Kumar SS, Suresh KS, Selvan GT, Thilakavel T (2013) Multi-criteria decision modelling approach for biodiesel blend selection based on GRA-TOPSIS analysis. Int J Ambient Energy. doi:10.1080/01430750.2013.789984

16. Liu J, Jiang X, Huang X, Wu S (2009) Morphological characterization of superfine pulverized coal particles. 1. Fractal characteristics and economic fineness. Energy Fuel 24:844-855, doi:10.1021/ef900954m

17. Wang S, Jiang XM, Wang Q, Han XX, Ji HS (2013) Experiment and grey relational analysis of seaweed particle combustion in a fluidized bed. Energy Convers Manage 66:115-120, doi:10.1016/j.enconman.2012.10.006

18. Wang H, Jiang X, Liu J, Lin W (2007) Experiment and grey relational analysis of CWS spheres combustion in a fluidized bed. Energy Fuel 21:1924-1930, doi:10.1016/j.enconman.2012.10.006

19. Han $X$, Jiang $X$, Liu J, Wang $H$ (2006) Grey relational analysis of N2O emission from oil shale-fired circulating fluidized bed. Oil Shale 23:99-109

20. Kuo Y, Yang T, Huang G (2008) The use of grey relational analysis in solving multiple attribute decision-making problems. Comput Ind Eng 55:80-93, doi:10.1016/j.cie.2007.12.002

21. Asian N, Shahrivar AA, Abdollahi H (2012) Multi-objective optimization of some process parameters of a lab-scale thickener using grey relational analysis. Sep Purif Technol 90:189-195, doi:10.1016/.j.seppur.2012.02.033

22. Liu S, Forrest J (2007) The current developing status on grey system theory. J Grey Syst 19:111-123

23. Saavedra A, Arce E, Miguez JL, Granada E (2013) Potential effect of uncertainty on the GRG interpretation. Grey Syst Theory Appl 3:121-128, doi:10.1108/GS-11-2012-0043

24. Pazo JA, Granada E, Saavedra A, Patino D, Collazo J (2010) Heterogenic solid biofuel sampling methodology and uncertainty associated with prompt analysis. Int J Mol Sci 11:2118-2133, doi:10.3390/ijms11052118

25. Patino D (2009) Análisis experimental de combustión de biomasa en un quemador de lecho fijo. Dissertation, University of Vigo (Spain)

26. Tuck G, Glendining M, Smith P, House J, Wattenbach M (2006) The potential distribution of bioenergy crops in Europe under present and future climate. Biomass Bioenergy 30:183-197, doi:10.1016/j.biombioe.2005.11.019

27. Saastamoinen J, Taipale R, Horttanainen M, Sarkomaa P (2000) Propagation of the ignition front in beds of wood particles. Combust Flame 123:214-226, doi:10.1016/S0010-2180(00)00144-9

28. Ryu C, Yang Y, Khor A, Yates N, Sharifi V, Swithenbank J (2006) Effect of fuel properties on biomass combustion: Part I. experiments - fuel type, equivalence ratio and particle size. Fuel 85:1039-1046, doi:10.1016/ j.fuel.2005.09.019

29. Mehrabian R, Scharler R, Obernberger I (2012) Effects of pyrolysis conditions on the heating rate in biomass particles and applicability of TGA kinetic parameters in particle thermal conversion modelling. Fuel 93:567-575, doi:10.1016/j.fuel.2011.09.054

30. James AK, Thring RW, Helle S, Ghuman HS (2012) Ash management review applications of biomass bottom ash. Energies 5:3856-3873, doi:10.3390/ en5103856

31. Anca-Couce A, Zobel N (2012) Numerical analysis of a biomass pyrolysis particle model: solution method optimized for the coupling to reactor models. Fuel 97:80-88, doi:10.1016/j.fuel.2012.02.033

32. Liao K, Yao Q, Wu X, Jia W (2012) A numerical corrosion rate prediction method for direct assessment of wet gas gathering pipelines internal corrosion. Energies 5:3892-3907, doi:10.3390/en5103892

33. Subbaya KM, Suresha B, Rajendra N, Varadarajan YS (2012) Grey-based taguchi approach for wear assessment of SiC filled carbon-epoxy composites. Mater Des 41:124-130, doi:10.1016/j.matdes.2012.04.051

34. Taylor RP, Hodge BK, James CA (1999) Estimating uncertainty in thermal systems analysis and design. Appl Therm Eng 19:51-73, doi:10.1016/ S1359-4311(97)00093-8

35. Joint Committee for Guides in Metrology (2008) Evaluation of measurement data. Guide to the expression of uncertainty in measurement., Available online: http://www.bipm.org/utils/common/documents/jcgm/JCGM_100_ 2008 E.pdf. Accessed 21 Jul 2014

36. Perez JF, Melgar A, Benjumea P (2012) Effect of operating and design parameters on the gasification/combustion process of waste biomass in fixed bed downdraft reactors: an experimental study. Fuel 96:487-496, doi:10.1016/j.fuel.2012.01.064

37. Fagerström J, Näzelius IL, Gilbe C, Boström D, Öhman M, Boman C (2014) Influence of peat ash composition on particle emissions and slag formation in biomass grate co-combustion. Energ Fuel 28:3403-3411, doi:10.1021/ ef4023543

38. Jenkins BM, Baxter LL, Miles TR Jr, Miles TR (1998) Combustion properties of biomass. Fuel Process Technol 54:17-46, doi:10.1016/S0378-3820(97)00059-3

39. González JF, González-García CM, Ramiro A, González J, Sabio E, Gañán J, Rodríguez MA (2004) Combustion optimisation of biomass residue pellets for domestic heating with a mural boiler. Biomass Bioenergy 27:145-154, doi:10.1016/j.biombioe.2004.01.004

40. Shin D, Choi S (2000) The combustion of simulated waste particles in a fixed bed. Combust Flame 12:167-180, doi:10.1016/S0010-2180(99)00124-8

41. Yin C, Rosendahl LA, Kær SK (2005) Grate-firing of biomass for heat and power production. Prog Energy Combust 34:725-754, doi:10.1016/ j.pecs.2008.05.002

\section{Submit your manuscript to a SpringerOpen ${ }^{\circ}$ journal and benefit from:}

- Convenient online submission

- Rigorous peer review

- Immediate publication on acceptance

- Open access: articles freely available online

- High visibility within the field

- Retaining the copyright to your article

Submit your next manuscript at $>$ springeropen.com 